\title{
The Cultivation of Humanistic Quality in College English Course System of Elite Program in Southwest University
}

\author{
Huang Jing \\ College of International Studies, Southwest University, Chongqing, 400715 China
}

Keywords: humanistic quality; Elite Program; College English; Southwest University

\begin{abstract}
College English course system is one part of Elite Program in key universities in China. The cultivation of humanistic quality contained in English education will be beneficial to the Elite Program. Southwest University has gained some experience in developing the competence of top students in the reform of course system. However, more contribution has to be done to improve the humanistic quality in the exploration.
\end{abstract}

\section{Current Status of College English Course System of Elite Program in China}

During recent 10 years, Elite Program is a critical part of teaching reform of key universities in China and increasing draws attention of the whole society. "Top-notch talent is the lasting power of national revival and strong support to achieve the great rejuvenation of the Chinese nation." As a matter of fact, some of the " 985 " and " 211 " universities in China carefully divide students into three target groups as the accomplishment of the goals of top talents. Following the mode of Elite Program as Peking University, Zhejiang University and Sichuan University, Southwest University also attempted to cultivate its top talents since the year of 2011, it established an independent college, Hanhong College, to carry out the Elite Program. Training top-notch talents is a conscious action of content development of universities. Students are strictly picked up from the whole campus, involving all the majorities. "As a goal, outstanding candidates are designed to be leading academic research scholars, innovative study experts and competitive practitioners of certain fields.”

Academic research scholars need solid and enriched basic knowledge and scientific research competence of one major which lay a good foundation to form his independence for future scientific program. Innovative study experts are future intelligent talents who are sensitive to new things and possess strong wills to dig out the unknown knowledge. They have wild-broad horizon and interdisciplinary research capacity. They are dare to challenge the clichés and authorities, brave enough to open a new scientific field and good at communicative skills. Competitive practitioners mean talents can meet with the market demands, quickly adapt to their future profession, and acquire some skills required by the position. Compared with the academic research scholars, this kind of talents have more practical skills and the ability to solve problems in a certain position.

The design of College English course should serve for the goal of Elite Program. What is the goal? What is the practical strategy to accomplish it? Basically, the cultivation of top talents differs from the normal university education, yet it follows the common rules of teaching and cultivation of normal graduates. As a pioneer of course model, Jilin University has already realized the relations among language skills, competence and comprehensive qualities. Students in experimental class are divided into two groups. The lower class focuses more on the training of language skills, and the advanced class tend to integrate more disciplinary contents. Generally, experts in English education think learners in China lack specific contents in spoken and written English, logic and critical perspectives as well. The target of English education should develop "talents of a comprehensive master of language skills, deep humanistic quality, broad horizon, critical thinking competence, creativity and responsibility.” (Hu Wen-zhong, Sun You-zhong, 2006) Actually, experimental class of elite program in Jilin University has already cleared its target as "strengthening language basis, weakening major background, teaching according to students’ aptitudes and levels”.

However, "there is the problem that lack of moral education and shortage of art education in 
research and practice.” Thus, humanistic quality and critical thinking competence are the ultimate goal of College English teaching, with the applied English skills as the evident goals, and through exchanging students program to broaden students' horizon and thus enhance their international competitiveness.

\section{The Cultivation of Humanistic Quality Sense in the Exploration of Course System of Southwest University}

In the curriculum model of Southwest University, the lower class period lasts for one and a half year. Students basically complete general education classes and across-major classes to have a good master of theoretical ideas and concepts, scientific spirit and humanistic quality. After that period, students can select majors, directions and courses according to their interests and practical situations. College English is one of the main courses from the lower period. Students in Hanhong College have more prestige of courses selection and of better teaching resources than other students in ordinary colleges. They enjoy quite individualized English teaching arrangements at first. In the consideration of course design in 2011, there were long-term basic College English class, and short-term lectures. The former contained Comprehensive English, Advanced English Viewing, Listening and Speaking English, English Reading, and Grammar and Writing; the latter included Phonetics, British and American literature history, Across-culture Communication, Religion in Britain and America, Academic Reading and Writing, Contemporary International Politics and Economy, TOEFL, GRE, and IELTS Training and Test Strategy, the Guidance of Oversea Study. Obviously, after one's multiple combination of College English and English major courses, the course periods are reducing, and the types of class become simpler. In the first year, teachers who had oversea experiences and advanced titles were more favored by the employment of Hanhong College.

The year of 2012 course curriculum adjusted a lot, cutting down all the lectures and advanced English courses. It guided students more towards language testing goals, such as passing CET 4\&6, TOEFL/IELTS. The deficiency is very clear, particularly just 2 periods, just viewing, listening and speaking class for the whole first semester, which was far from the quantity of language input, let alone humanistic elements in the consideration of opening courses. CET 4\&6 training seemed unnecessary for these top talents who were capable of passing the test but hard to gain high score for lack of sufficient language input and it was not beneficial to cultivate their humanistic quality. To be frank, they were trained to be just better test examinees.

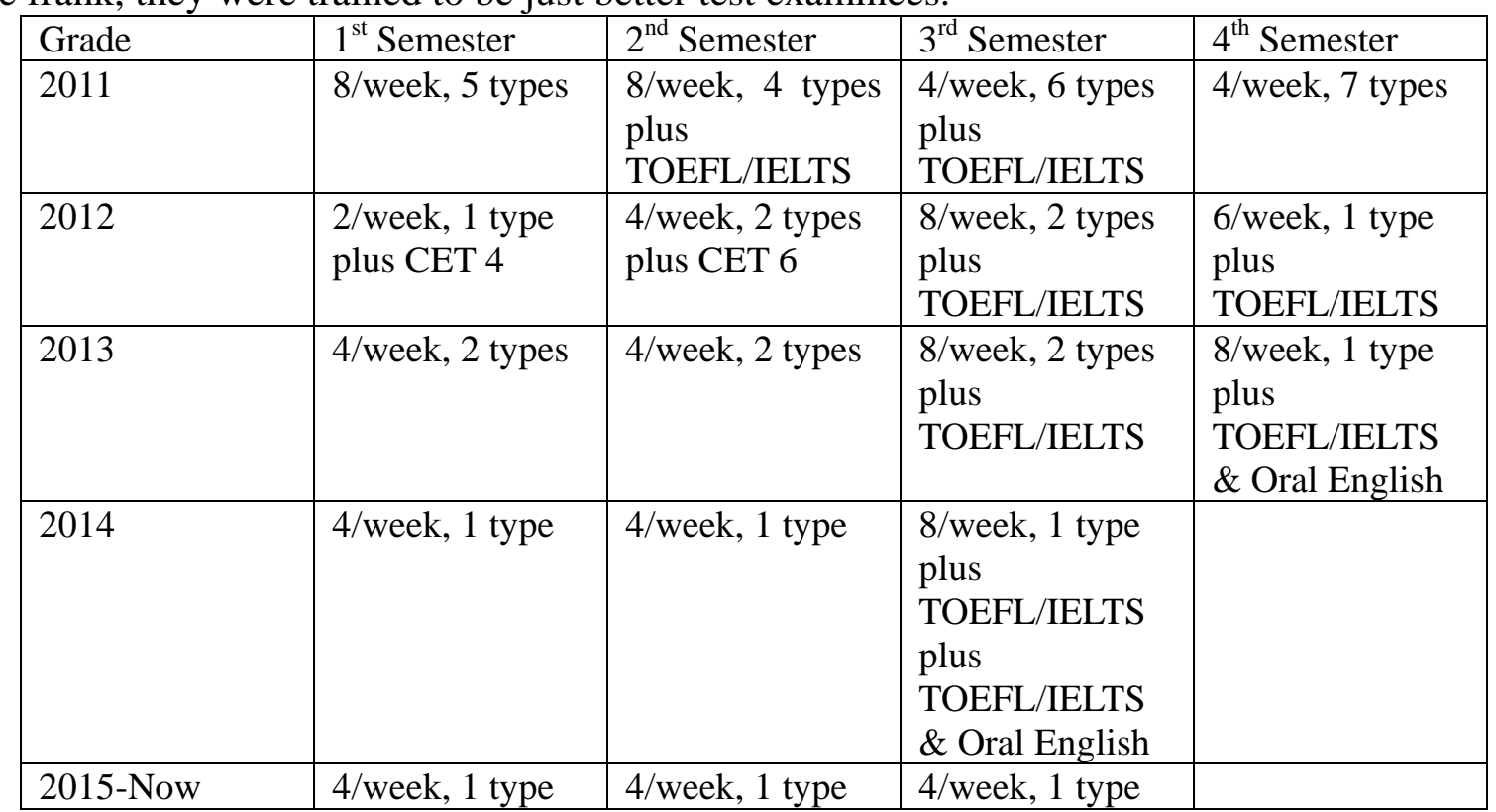

It seemed in the following years, the in-class time was shortened and test-based training class was also canceled. However, from the other perspective, the deliberately weakening the sense of tests is good for top students and teachers to rethink the value and orientation of College English 
course and return to education primitives. There are still a long way to arrive at a good model, teachers are faced with great challenge to cultivate students' language competence as well as to enhance their humanistic qualities. Content-based and research-oriented teaching approach has been more considered instead of test-based solely teaching approach.

Teachers who open classes in Hanhong College apply for scientific research programs to reflect on the topic of curriculum, analyze the textbooks used and explore and edit more individualized textbooks for students. Until now, there are four textbooks explored and put into use. Also, teachers emphasize students to take good use of their talents and time. Students are encouraged to read more out-of-class books and watch electronic materials on knowledge introducing western countries, including everyday life, history, education system, medical and hospital system, politics and economy, literature, etc. In addition, students are oriented to participate in all levels of English public speech contests, reading contests and writing contests, and won abundant prizes. These activities develop students' humanistic capacity than only language skill tests. And as for the way of assessment, teachers take formative evaluation approach to assess students' performance. Teachers establish study files for each student and record their period progress and deficiency in English study. Besides that, students are required to divide to relatively fixed groups to accomplish some reading and speaking tasks, and do presentation according to schedule in class. Students will comment each other within groups and other students as well. During the long term of in-class and out-of-class observation, the file, peer comments and the formal tests are the main references for teachers to assess the students and give every individual appropriate guidance to go on with their study.

Although the the importance of College English has transferred from language learning itself towards the tendency of humanistic elements, there are still some problems in the curriculum design. First of all, it needs to be much clearer in the teaching concepts and arrangements in the service of improving students' humanistic quality. It seems that there has no clear mind in the course arrangement, at least no clear distinction between the first year and the second year of English study. Second, there are no more flexible and optional courses for students to choose. Actually, students differs in their language performance and content structure due to their talents, interests and background. They could choose the course they need to make up knowledge shortage, develop their interests and curiosity, or to broaden their horizon if they would have more optional courses. Comparatively, ordinary students in Southwest University do have more choices after the teaching reform since 2014. They are divided into 5 levels according to the tests at the beginning of their university year. There are about 20 courses available covering language skills training, literature, culture and customs, advanced academic writing and so on. Students can choose one of them after the first period of general College English course. It's rather pitiful the teaching reform is backward of Hanhong College, which mainly due to the neglection and ignorance of the real importance of humanistic quality cultivation in English study.

\section{Evaluation and Suggestion on College English Course System}

At first, there were too many courses and too many teachers for students. Gradually, the type of English courses reduced a lot, and students had on more choice. What are the causes for a variety of courses at first, and then much simpler courses in the following years? Is it good for students to develop their humanistic quality?

Due to the attentive consideration of the whole university and the high expectation to the top students at first, the most extraordinary English teachers are assigned to give lectures. The result could be judged from two aspects. Students were expected to have more knowledge about western countries but had to pass all kinds of tests at the same time. They didn't have time to acquire so much knowledge and prepared the exams simultaneously. Later, the course type reduced and the goal went directly to pass the tests which directed students to another extreme situation. At last, the course comes back to the general English. Although teachers do some extra efforts to improve students humanistic quality, but the current course period are not enough and the goal is rather vague for the real accomplishment of promoting students' humanistic quality. Part of the reason is 
the recognition of educating the top talents should adhere to the rule of education itself, no too much expectation within a short time and part of it is teachers' resources reducing quite a lot. And the third reason is there are more experimental classes set up in other Colleges, which challenge the status of Hanhong College and distribute the teachers and students resources.

It is essential to reform the present curriculum. Faced with the status quo, first, more culture-based and content-based courses need to put into English class. British and American literature, humanities courses, culture comparative course, and corresponding teaching models are crucially important in the whole course design system. Second, clear mind of progressive courses available in each semester is the first guarantee. Some successful cases have already shown the significance of progressive course model are prior to general English course. For the four semesters in universities, it has three level courses for students to choose, EGP (English for General Purposes, covering English language skills training), ECP (English for Culture Purposes, covering British and American culture, literature and history knowledge), and EGAP (English for General Academic Purposes, covering academic reading, listening, speaking and writing training). This model can be simulated if the university really plan to cultivate students to be the future leaders, experts and entrepreneurs. Whatever the case is, a good balance between general language skill target and humanistic quality needs to keep. Third, the relative management department should devote more time and energy to care about the long-term development of students and ensure teachers opportunities to do research, exchange experiences by visiting other universities and even organize cross-disciplinary discussion collectively focus on improving students' comprehensive quality.

\section{Conclusion}

In order to enhance the cultivation of elite students' humanistic quality, it is still on the way for Southwest University to explore more scientific course system. No hurry or hesitation. Ensure and foreground the importance the humanistic quality in the consideration of the long-term development of top talents. College English should design its courses based on practical situation with an appropriate development of corresponding course system and respect the natural rule of language acquisition and the process of knowledge planted structure.

\section{Acknowledgment}

This paper is supported by the Teaching Reform Project of Southwest University "The deficiency of humanistic quality in Elite Program in universities and the solution strategy" (2016JY107).

\section{References}

[1] Zhou Guangming, Duan Shukai, Du Binheng, el. "On typical mode and practice in cultivating creativity of top talents,” Journal of Southwest China Normal University (Natural Science Edition), 2013(5):150-157.

[2] “The Implementation plan of Elite Program of Southwest University in 2011”; “College English course curriculum of Hanhong College of Southwest University in 2011”.

[3] Hu Wenzhong, Sun Youzhong. "On strengthening humanistic education in English language curriculum,” Foreign Language Teaching and Research. 2006(5):243-247.

[4] Qu Xin, Zhang Fengjuan \& Wang Xu. "Exploring the Elite Program College English Teaching Model and Effectiveness,” Foreign Languages in China. 2013(5):13-18.

[5] Zeng Dejun, Ke Li. "The research review on the topic about training top-notch innovative talents for recent 10 years,” Higher Education of Science. 2013(4):1-8.

[6] Liu Yanqin, Luan Shuwen. "Research on cultivation model of “3E” foreign language proficiency of top creative talents,” Shandong Foreign Language Teaching. 2016(2):41-48. 